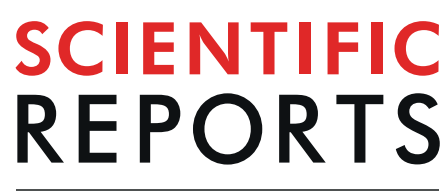

\title{
Rapid Response High Temperature Oxygen Sensor Based on Titanium Doped Gallium Oxide
}

Sandeep Manandhar ${ }^{1}$, Anil K. Battu ${ }^{1}$, Arun Devaraj $\mathbb{1}^{3}{ }^{3}$, V. Shutthanandan², S. Thevuthasan ${ }^{2}$ \& C.V. Ramana ${ }^{1 *}$

Real-time monitoring of combustion products and composition is critical to emission reduction and efficient energy production. The fuel efficiency in power plants and automobile engines can be dramatically improved by monitoring and controlling the combustion environment. However, the development of novel materials for survivability of oxygen sensors at extreme environments and demonstrated rapid response in chemical sensing is a major hindrance for further development in the field. Gallium oxide $\left(\mathrm{Ga}_{2} \mathrm{O}_{3}\right)$, one among the wide band gap oxides, exhibit promising oxygen sensing properties in terms of reproducibility and long term stability. However, the oxygen sensors based on $\beta-\mathrm{Ga}_{2} \mathrm{O}_{3}$ and other existing materials lack in response time and stability at elevated temperatures. In this context, we demonstrate an approach to design materials based on Ti-doped $\mathrm{Ga}_{2} \mathrm{O}_{3}$, which exhibits a rapid response and excellent stability for oxygen sensing at elevated temperatures. We demonstrate that the nanocrystalline $\beta-\mathrm{Ga}_{2} \mathrm{O}_{3}$ films with $5 \%$ Ti significantly improves the response time ( $\sim 20$ times) while retaining the stability and repeatability in addition to enhancement in the sensitivity to oxygen. These extreme environment oxygen sensors with a rapid response time and sensitivity represent key advancement for integration into combustion systems for efficient energy conversion and emission reduction.

Recent attention to climate change and global warming has directed enormous global interest in reducing carbon dioxide $\left(\mathrm{CO}_{2}\right)$ emissions to the environment. The major contributor to $\mathrm{CO}_{2}$ emission from human activities is from the energy conversion, especially the fossil fuel combustion for electricity, heat and transportation ${ }^{1,2}$. The strict regulation and mandates of governments to protect environments has also motivated the energy and transportation sectors to research in emission reduction and environmental protection. While transportation industry is trying to meet these stringent $\mathrm{CO}_{2}$ emission standards by reducing vehicle weight ${ }^{3-5}$, extensive research and development of new materials is needed to meet the weight reduction which is highly expensive and only a long-term solution. However, the emissions from fossil fuel combustion can be greatly reduced in both energy and transportation industry if internal engine combustion conditions are efficiently controlled. The optimization of combustion environment requires a reliable and rapid response chemical sensor to monitor the partial pressure of oxygen $\left(\mathrm{pO}_{2}\right)$ during combustion. Hence, in recent years, the demand of fast and reliable oxygen sensing is rising exponentially $y^{6,7}$. No doubt that the earlier investigations resulted in a great success in fundamental understanding and development of commercialized thin film sensors based on metal oxides, such $\mathrm{as}_{\mathrm{SnO}}$ for domestic gas leak alarms, solid-electrolyte $\mathrm{ZrO}_{2}$ sensors for detecting oxygen concentration in automobile exhaust system, and $\mathrm{TiO}_{2}$-based lambda lean burn sensors ${ }^{8,9}$. However, addressing the poor stability, reliability, and slow response still remains a technological challenge. Wide band gap $\beta-\mathrm{Ga}_{2} \mathrm{O}_{3}$ has shown promise as a stable extreme environment chemical sensor ${ }^{10-12}$ due to excellent long term thermal stability (melting point $\sim 1780^{\circ} \mathrm{C}$ ) against interfering gases and humidity ${ }^{13}$. Due to the high thermal stability of $\beta-\mathrm{Ga}_{2} \mathrm{O}_{3}$, the upper limit for operating temperature is $\sim 1000^{\circ} \mathrm{C}^{6} . \beta-\mathrm{Ga}_{2} \mathrm{O}_{3}$ is an $\mathrm{n}$-type semiconductor at elevated temperatures and its conductivity is based on an oxygen deficiency of the crystal lattice. The resulting oxygen vacancies are ionized to form donors ${ }^{14}$. The material exhibits the same charge carrier mobility in the monocrystalline and in the polycrystalline state which means electron mobility is independent of grain boundaries ${ }^{14}$. It is also found that the sensors based on $\beta-\mathrm{Ga}_{2} \mathrm{O}_{3}$

\footnotetext{
${ }^{1}$ Center for Advanced Materials Research CMR, University of Texas at El Paso, El Paso, Texas, 79968, USA. 2Environmental Molecular Sciences Laboratory, Pacific Northwest National Laboratory, Richland, Washington, 99352, USA. ${ }^{3}$ Physcial \& Computational Sciences Directorate, Pacific Northwest National Laboratory, Richland, Washington, 99352, USA. *email: rvchintalapalle@utep.edu
} 

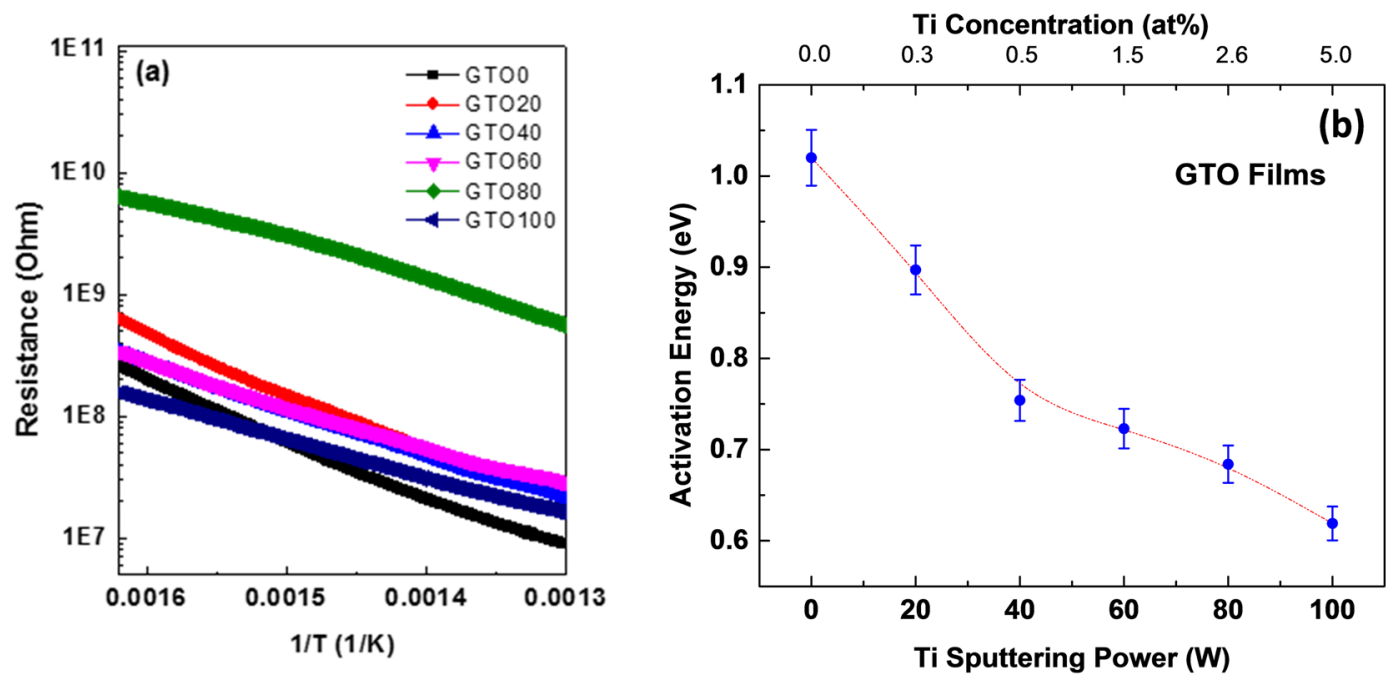

Figure 1. (a) Electrical data of GTO films. Arrhenius plots are shown for samples with variable Ti content. (b) Activation energy of GTO films. Continuous decrease in $\mathrm{E}_{\mathrm{A}}$ values with Ti incorporation into $\mathrm{Ga}_{2} \mathrm{O}_{3}$ can be noted.

films show high reproducibility and stability in the gas-sensitive electrical properties ${ }^{6}$. Also there has been some reports of $\beta-\mathrm{Ga}_{2} \mathrm{O}_{3}$ thin films operating as surface-control type sensors when exposed to a reducing gas below $900{ }^{\circ} \mathrm{C}^{15}$ and bulk type sensor when exposed to an oxygen above $900^{\circ} \mathrm{C}^{16}$. Despite the advantages, response time ( $>1 \mathrm{~min}$ ) for $\beta-\mathrm{Ga}_{2} \mathrm{O}_{3}$ based oxygen sensors ( $\left.\sim 60-200 \mathrm{~s}\right)$ are still inept for controlling efficient combustion ${ }^{17,18}$. In this context, in the present work, we demonstrate an approach based on selective doping metal ions into $\beta-\mathrm{Ga}_{2} \mathrm{O}_{3}$ to realize reliable and rapid response high-temperature oxygen sensors for operation in harsh environments.

As demonstrated and reported previously ${ }^{11,19-24}$, doping with carefully chosen metal ions can significantly alter the properties and electrical response of $\beta-\mathrm{Ga}_{2} \mathrm{O}_{3}$, making it suitable for high temperature chemical sensing applications. From an optical properties point of view, doping $\beta-\mathrm{Ga}_{2} \mathrm{O}_{3}$ with $\mathrm{Sn}, \mathrm{Cr}, \mathrm{Cu}, \mathrm{Ti}, \mathrm{Mo}$, In, Fe, or W has been reported to induce changes in the optical absorption and band gap ${ }^{11,19-24}$. In literature, there has been some work in improving gas sensing performance of $\beta-\mathrm{Ga}_{2} \mathrm{O}_{3}$ by doping $\mathrm{Ce}, \mathrm{Sb}, \mathrm{W}$ and $\mathrm{Zn}^{18}$. The advantage of using dopants like $\mathrm{Ce}^{4+}, \mathrm{Sb}^{5+}, \mathrm{W}^{6+}$ is due to similar ionic radii which might allow the substitutional lattice sites resulting in lower sensor resistivity. However, the fastest response from these dopants was still $\sim 1 \mathrm{~min}(60 \mathrm{~s})^{18}$, which is unacceptable in managing combustion process efficient. Here in this paper, we report on an innovative approach to tailor the functionality of $\beta-\mathrm{Ga}_{2} \mathrm{O}_{3}$ by doping Ti to dramatically improve the response time of the oxygen sensor while retaining the thermal stability and reliability of $\beta-\mathrm{Ga}_{2} \mathrm{O}_{3}$ for high-temperature sensor applications. In the previous work, we report on the direct, functional relationship between the structural and optical properties of titanium (Ti)-incorporated $\mathrm{Ga}_{2} \mathrm{O}_{3}(\mathrm{GTO})$, where tailor-made materials for optical and photocatalytic applications are readily possible ${ }^{19}$. The hypothesis postulated based on the outcomes is that combining advantages of Ga- and $\mathrm{Ti}$ - based oxides through a selective doping of Ti into $\beta-\mathrm{Ga}_{2} \mathrm{O}_{3}$ and/or forming a $\mathrm{Ga}$-Ti-O composite can enhance the sensor performance. The impetus is derived from the following considerations. Titanium, as a dopant, is attracted to oxygen and excess $\mathrm{Ti}$ will result in $\mathrm{TiO}_{2}$ phase. $\mathrm{TiO}_{2}$, a wide band gap semiconductor, has also been intensively studied as a key material for fundamental research and numerous technological applications because of its stability, non-toxicity, high abundance and low $\cos ^{25}$. Furthermore, similar to $\beta-\mathrm{Ga}_{2} \mathrm{O}_{3}, \mathrm{TiO}_{2}$ is also an $n$-type semiconductor with a potential as a sensor ${ }^{26-28}$. It is noted that oxygen vacancies in transition metal oxides such as $\mathrm{TiO}_{2}$ are much more mobile than cations ${ }^{29}$, and it is reasonable to consider the movement of oxygen ions (or oxygen vacancies) as opposed to cations ${ }^{30}$. In addition, Shannon ionic radii ${ }^{31}$ of $\mathrm{Ti}^{4+}$ ionic radii in both octahedral and tetrahedral coordination closely matches with that of $\mathrm{Ga}^{3+}$. Hence, we propose and demonstrate designing more efficient materials for high-temperature oxygen sensing in harsh environments is readily possible by selectively doping Ti into $\beta-\mathrm{Ga}_{2} \mathrm{O}_{3}$.

\section{Results and Discussion}

Sensor performance and mechanism. The temperature dependent electrical data, which serves the baseline characteristics for sensor applications, of GTO samples are shown in Fig. 1. It is generally accepted that barrier formation between grains is responsible for the sensor conductivity and that these barriers have a Schottky-type nature ${ }^{32}$. Therefore, as a first step, determination of activation energy is quite important for utilization of GTO for sensor applications. The temperature-dependent electrical data (Fig. 1a; Arrhenius plots) of GTO samples were analyzed to obtain the activation energy of the films using the relation:

$$
R=R_{\infty} e^{\left(-\frac{E_{A}}{k T}\right)}
$$

where $R_{\infty}$ is the resistance at infinite temperature, $E_{A}$ is the activation energy, $k$ is the Boltzmann constant, $T$ is the absolute temperature, and $\mathrm{R}$ is the resistance. The $\mathrm{E}_{\mathrm{A}}$ values determined are presented in Fig. $1 \mathrm{~b}$, where the 


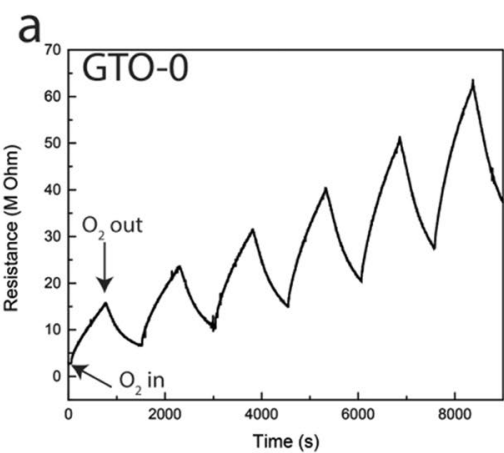

b
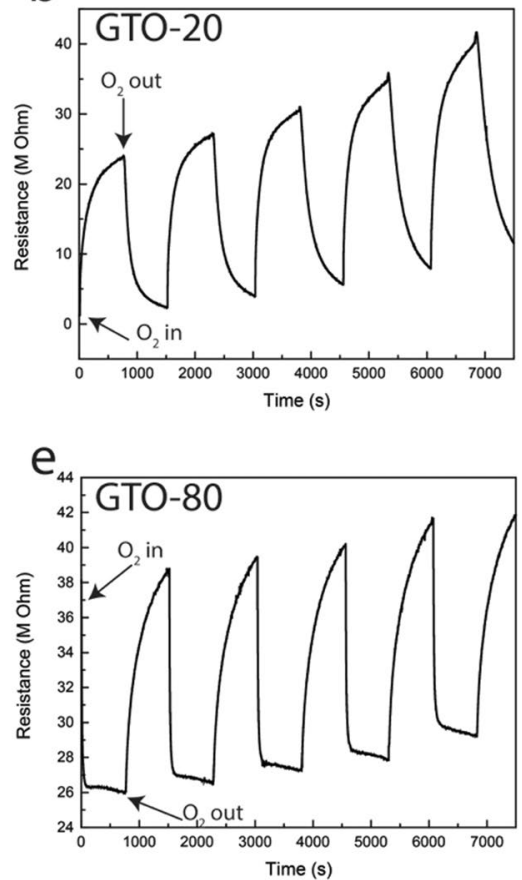

C
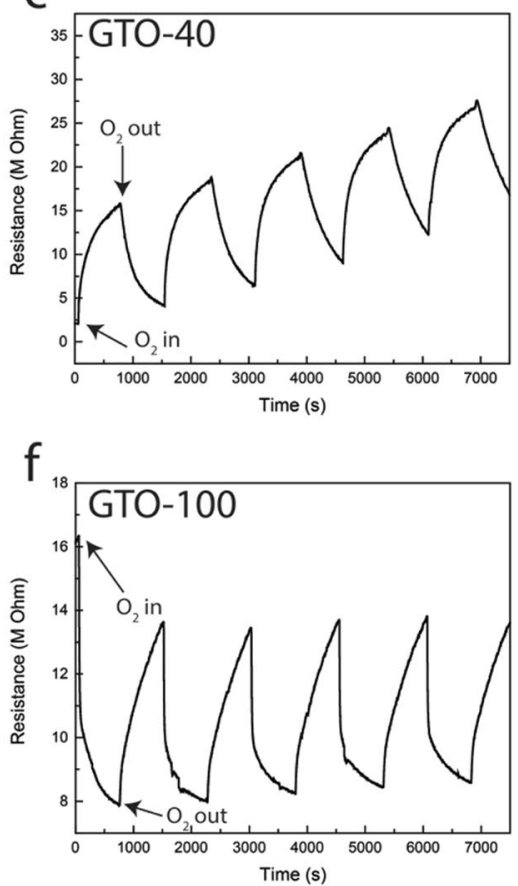

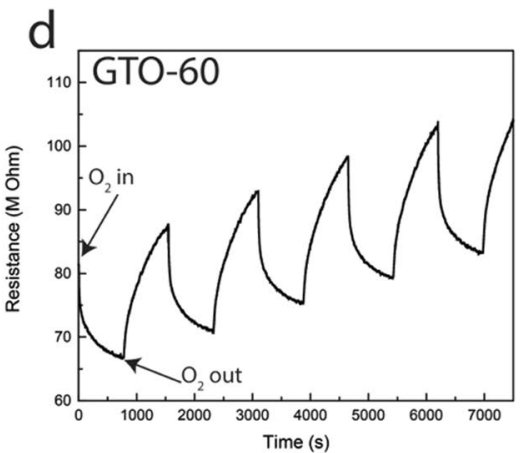

Figure 2. Gas sensing performance test. (a) GTO-0. (b) GTO-20. (c) GTO-40. (d) GTO-60. (e) GTO-80. (f) GTO-100.

effect of $\mathrm{Ti}$ content on the $\mathrm{E}_{\mathrm{A}}$ values is shown. It can be seen that the $\mathrm{E}_{\mathrm{A}}$ continuously decrease with increasing Ti in $\mathrm{Ga}_{2} \mathrm{O}_{3}$. This observation is imperative since the $\mathrm{E}_{\mathrm{A}}$ reduction is expected to contribute the enhanced sensitivity. The $\mathrm{E}_{\mathrm{A}}$ value for intrinsic $\mathrm{Ga}_{2} \mathrm{O}_{3}$ films was $1.02 \mathrm{eV}$, which reduces to a final value of $0.62 \mathrm{eV}$ when the Ti concentration is $\sim 5$ at\%. Significant reduction in $\mathrm{E}_{\mathrm{A}}$ is an indication that thermal energy required for oxygen detection becomes smaller by the incorporation of Ti-ions into $\mathrm{Ga}_{2} \mathrm{O}_{3}$.

The oxygen sensor response data of GTO films are shown in Fig. 2. The performance characteristics were evaluated at $700^{\circ} \mathrm{C}$ in terms of initial sensitivity and response time. The data shown are obtained in the experiments conducted under different $\mathrm{pO}_{2}(8-40 \mathrm{~Pa})$ in cyclic periods of pure Ar flow for a constant time followed by $\mathrm{Ar} / \mathrm{O}_{2}$ flow for the same time period. The repeatability and stability of the sensors was evaluated (Fig. 2) at $700{ }^{\circ} \mathrm{C}$ for several hours as a function of $\mathrm{pO}_{2}$. All of the GTO films demonstrated the stability and repeatability for the extended duration of the tests $(\geq 100 \mathrm{~h})$. No discontinuity or breakdown was observed over the range of $\mathrm{pO}_{2}$ examined. Intrinsic $\mathrm{Ga}_{2} \mathrm{O}_{3}$ response also presented changes in the resistance value under Ar exposure, corresponding the polarization effects caused by the ionic conductivity of the films, and the constant increment on the base resistance is attributed to the grain boundary capacitance of the films ${ }^{33}$. As shown Fig. 2, it can be observed that GTO-0, GTO-20, and GTO-40 responded by the increase in resistance when oxygen is introduced. This response of pure $\mathrm{Ga}_{2} \mathrm{O}_{3}$ has been previously observed in the literature ${ }^{17}$. However, the changes in response behavior becomes evident when the Ti content becomes appreciable. For Ti a concentration of $\geq 1.5$ at $\%$, the sensor response to oxygen flips and resistance now decreases after oxygen is introduced and vice-versa. This remarkable behavior observed for GTO films under $\mathrm{pO}_{2}$ is totally different and has not been achieved or reported earlier for intrinsic $\mathrm{Ga}_{2} \mathrm{O}_{3}$. Also, the changes are rapid; the response behavior in GTO films is rather instantaneous and occur rapidly upon oxygen release into the argon stream. However, when the oxygen was cut off, the reversal to original resistance takes bit of a longer time. This phenomenon confirms that out-diffusion of oxygen is relatively slow. To ensure reproducibility, interval between successive measurements is set to $\sim 10 \mathrm{~min}$.

The response time GTO sensors are determined, using the standard procedures, from the sensor characteristics at various $\mathrm{pO}_{2}$ (Fig. 2). The response time for intrinsic $\mathrm{Ga}_{2} \mathrm{O}_{3}(\mathrm{GTO}-0)$ is $80 \pm 10 \mathrm{~s}$, whereas for the films deposited with 5 at $\%$ of Ti-doped $\mathrm{Ga}_{2} \mathrm{O}_{3}$ exhibits a rapid response time of only $4 \pm 1 \mathrm{~s}$. This is a remarkable result and demonstrates the effect of Ti into $\mathrm{Ga}_{2} \mathrm{O}_{3}$ to promote oxygen sensor performance. The sensor response data is presented in Fig. 3a, where the results indicate that increasing Ti content in $\mathrm{Ga}_{2} \mathrm{O}_{3}$ decreases the response time i.e., improves the sensor performance. The results indicate that the 5 at $\%$ Ti doped $\mathrm{Ga}_{2} \mathrm{O}_{3}$ is nearly $\sim 20$ times faster as compared to intrinsic $\mathrm{Ga}_{2} \mathrm{O}_{3}$. Note that the response time can be influenced by the surface reactions rate or/and the diffusion rate. When $\mathrm{pO}_{2}$ is increased, the oxygen molecules adsorbed at the surface split and occupy the vacancies near the surface. A diffusion process of oxygen inside the film, across the grain boundaries, will reestablish equilibrium with the gas phase ${ }^{15}$.

The materials that respond to change in $\mathrm{pO}_{2}$ in the upper-temperature range $\left(700^{\circ} \mathrm{C}\right.$ and above $)$ are reflecting the equilibria between the atmosphere and their bulk stoichiometry. In general, the relationship between oxygen partial pressure and the electrical conductivity of the mixed valence oxide sensor may be represented ${ }^{34}$ by: 
Ti Concentration (at\%)

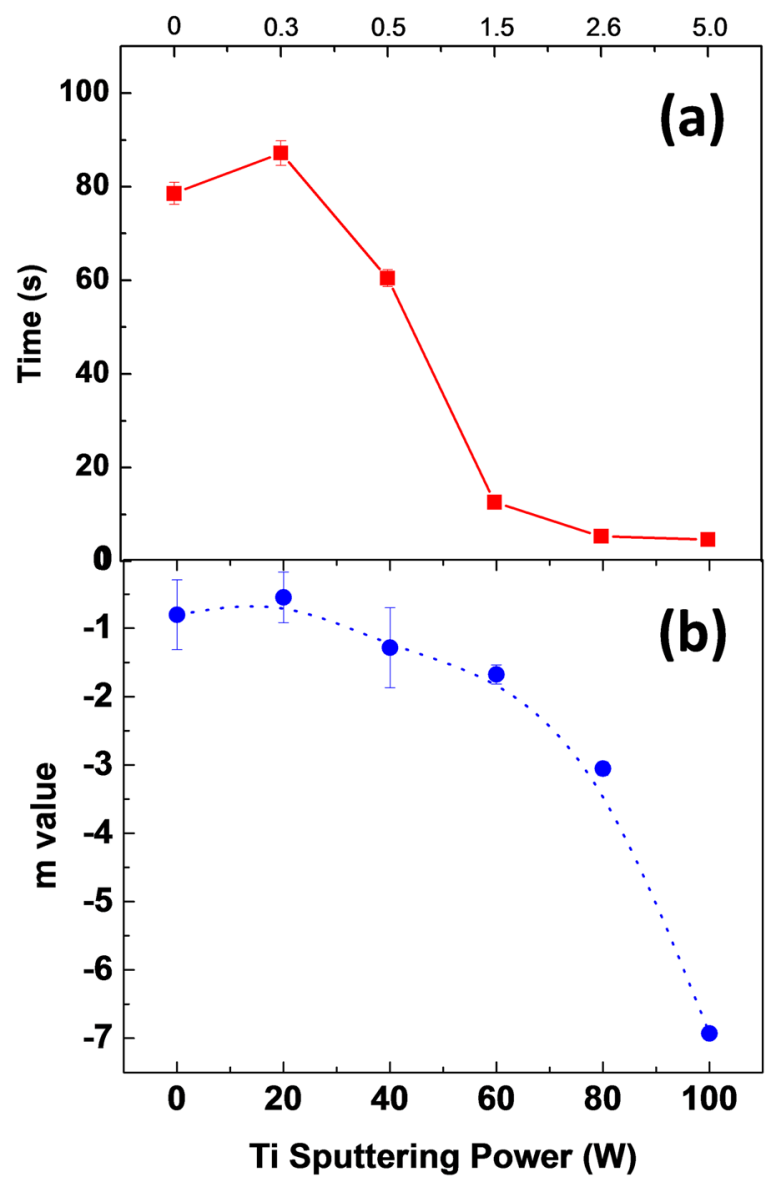

Figure 3. Oxygen sensor performance of characteristic values of GTO films. (a) Response time. (b) m value determined from functional electrical characteristics of GTO.

$$
\sigma=A * \exp \left[-E_{A} / k T\right] / p O_{2}^{1 / m}
$$

where $\mathrm{A}$ is a constant, $\mathrm{pO}_{2}$ is the partial pressure of oxygen, and $\mathrm{m}$ is a parameter determined by the carriers $(n$ or $p$ type) and defects in the oxide ${ }^{34,35}$ while other parameters were defined already in Eq. (1) The value of $|\mathrm{m}|$ is the sensitivity of the sensor; higher the $|\mathrm{m}|$ value, higher the sensitivity and vice versa ${ }^{35}$. The electrical data at various $\mathrm{pO}_{2}$ were used to calculate the m-values, which are presented in Fig. 3b. In intrinsic $\mathrm{Ga}_{2} \mathrm{O}_{3}$ films (GTO-0), the $\mathrm{m}$-value is -0.8 , which is quite higher than theoretical value (at $1000^{\circ} \mathrm{C}$ ) of -4 as presented in the literature ${ }^{13,17}$. However, the Ti doping in $\mathrm{Ga}_{2} \mathrm{O}_{3}$ shows the reduction of $\mathrm{m}$ value up to -6.92 for GTO-100, i.e., Ti concentration of 5 at\%. From Eq. 2, it is clear that the lower value of $m$ value corresponds to a higher sensitivity of sensor in terms of its response to changes in $\mathrm{pO}_{2}$. Also, lower value of $\mathrm{E}_{\mathrm{A}}$ corresponds to lower sensitivity to the temperature fluctuations. The value of $\mathrm{m}$ for pure $\mathrm{Ga}_{2} \mathrm{O}_{3}$ (GTO-0) and highest Ti concentration of 5 at $\%$ (GTO-100) are -0.8 and -6.92 , respectively, where lower $\mathrm{m}$ value of GTO-100 demonstrates a better oxygen sensitivity. Similarly, GTO-100 samples with lowest $\mathrm{E}_{\mathrm{A}}(0.62 \mathrm{eV})$ implies precise measurements of $\mathrm{pO}_{2}$ when employed for oxygen sensing.

Structure. In order to better account for the observed sensor performance and to understand the structural changes with Ti, Transmission Electron Microscopy (TEM) analysis has been performed on GTO-100. The data obtained is shown in Fig. 4. The changes in microstructure due to doping is evident in Fig. 4. Bright-field TEM images reveal multiple layers of the samples indicating a $\mathrm{Ga}-\mathrm{Ti}-\mathrm{O}$ nanocomposite on $\mathrm{Si}$. The top two layers are the Pt deposited using electron beam and ion beam subsequently during FIB lift out process (Fig. 4a). The ring patterns from the selected area electron diffraction (SAED) (Fig. 4b) confirms multiple phases in the sample, where the strongest peaks can be indexed to $\beta-\mathrm{Ga}_{2} \mathrm{O}_{3}$ but weaker intensity peaks are probably mixed with $\mathrm{TiO}_{2}$ (anatase). This overlap of multiple rings makes it impossible to confirm $\mathrm{TiO}_{2}$ phases accurately but confirms the crystallinity of the nanocomposite even with highest Ti doping (5\% Ti at\%) in $\beta-\mathrm{Ga}_{2} \mathrm{O}_{3}$.

Surface and Interface Chemistry. To probe the chemical changes and better understand the dopant Ti chemistry in $\beta-\mathrm{Ga}_{2} \mathrm{O}_{3}$ and identify the $\mathrm{TiO}_{2}$ phase which was inconclusive in TEM, X-ray Absorption Near Edge 
a

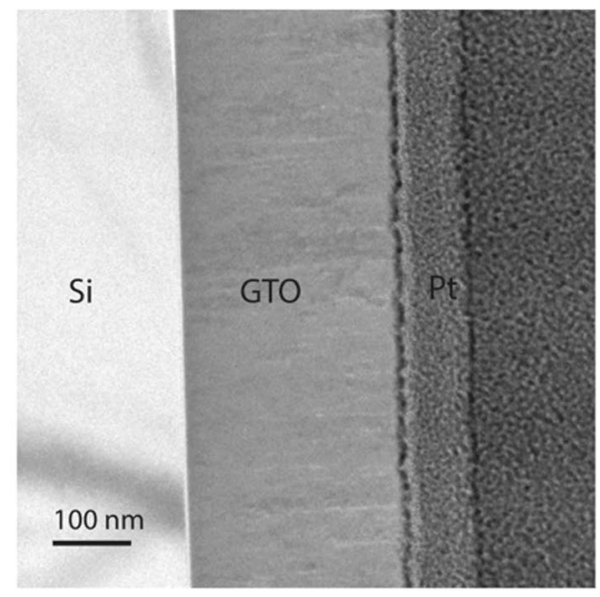

b

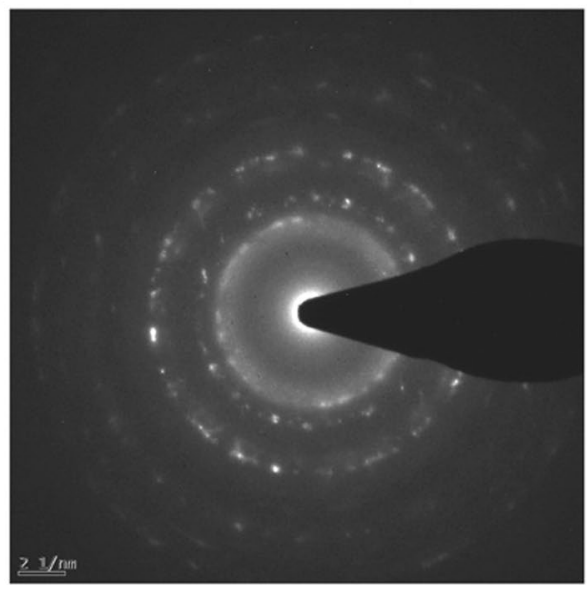

Figure 4. TEM and Selected Area Electron Diffraction (SAED) paired image of GTO-100 (5\% Ti at\%). (a) Bright-field transmission electron micrograph of a GTO-100. (b) SAED of the GTO-100 layers demonstrates ring pattern.

Structure (XANES) was employed. In XANES, the fine structure observed above the edge, so-called white line, reflects the local site symmetry around the $\mathrm{X}$-ray absorbing atom, the analysis of this region is for the fingerprint of the elements. It is well known that $\beta-\mathrm{Ga}_{2} \mathrm{O}_{3}$ has a spinel structure, containing $\mathrm{Ga}$ atoms in both tetrahedral and octahedral sites ${ }^{36,37}$. The Ga L-edge spectra shown in Fig. $5 \mathrm{a}$ is due to excitation of electrons in the $2 \mathrm{p}_{3 / 2}$ orbital of $\mathrm{Ga}$, leading to sharp increase in absorption of $\mathrm{Ga}$-containing materials at $1116.4 \mathrm{eV}^{38}$. However, the edge for $\mathrm{Ga}$ in $\mathrm{Ga}_{2} \mathrm{O}_{3}$ is shifted to $1120 \mathrm{eV}$ due to valence dependency which causes edges to shift ${ }^{39}$. Therefore, the first peak labeled A (or edge) in Ga L edge spectrum is assigned to Ga atoms in octahedral sites while subsequent peak labeled $\mathrm{B}$ is assigned to $\mathrm{Ga}$ in tetrahedral sites ${ }^{37}$. As the Ti concentration is steadily increased the signature peak of tetrahedral $\mathrm{Ga}$ atoms is diminished, which is presumably due to the replacement of Ga atoms in tetrahedral sites by $\mathrm{Ti}$ atoms.

In Fig. 5b, O K-edge spectra of GTO samples is shown along with the $\mathrm{TiO}_{2}$ standard. The O K-edge spectra for $\mathrm{TiO}_{2}$ standard matches signature features of anatase ${ }^{40}$ which confirms the $\mathrm{TiO}_{2}$ phase. In anatase $\left(\mathrm{TiO}_{2}\right.$ standard), first two peaks at low energy ( $\mathrm{I}$ and II) is due to dipole transitions to band states of $\mathrm{t}_{2 \mathrm{~g}}-\mathrm{e}_{\mathrm{g}}$ symmetry separated by the "ligand-field splitting" of $\mathrm{O} 2 \mathrm{p}$ states hybridized with the Ti $3 \mathrm{~d}$ states localized at the Ti sites ${ }^{41}$. The next two peaks (III and IV) in $\mathrm{TiO}_{2}$ standard is due to transitions to oxygen $2 \mathrm{p}$ hybridized with $\mathrm{Ti} 4 \mathrm{p}$ states of respective local symmetry $b_{3}$ and $e$ in their octahedral environment ${ }^{40}$. The $\mathrm{O}$ K-edge XANES spectrum of the $\mathrm{Ga}_{2} \mathrm{O}_{3}(\mathrm{GTO}$ $0)$ nanostructure sample is quite different from that of the $\mathrm{TiO}_{2}$ standard. For the GTO-0 sample, XANES spectrum exhibits two main peaks at $\sim 535 \mathrm{eV}$ and $\sim 542 \mathrm{eV}$ (A and B. respectively), similar to that of the $\beta-\mathrm{Ga}_{2} \mathrm{O}_{3}{ }^{42}$. Also from the crystal structure, it can be deduced that oxygen also resides in both octahedral and tetrahedral sites. Here, the difference of the $\mathrm{O}$ K-edge XANES spectra shown in Fig. $5 \mathrm{~b}$ between the two samples $\left(\mathrm{TiO}_{2}\right.$ standard and GTO-0) is the pre-edge feature due to Ti doping after GTO- 60 . This pre-edge $(\sim 530 \mathrm{eV})$ arise from the existence of an energy state in the band gap. In Fig. 5c, Ti L-edge XANES spectra of GTO samples are shown, but there was no titanium detected by XANES below for GTO-20. For anatase $\left(\mathrm{TiO}_{2}\right)$ standard and all GTO samples, two sets of peaks are observed which are separated by $\sim 6 \mathrm{eV}$. This splitting is due to core-hole spin-orbit splitting of the $2 \mathrm{p}$ levels ${ }^{41,43}$. It is believed that the structure of these two sets of peaks is from splitting of the d-derived final states into $t_{2 g}$ - and $e_{g}$-like levels ${ }^{44,45}$. This two set of the peak is also seen in GTO samples where titanium is above the detection limit in XANES. This XANES study basically suggests Ti doping in $\beta-\mathrm{Ga}_{2} \mathrm{O}_{3}$ substitutes at tetrahedral position but at higher concentration Ti phase separates in $\mathrm{TiO}_{2}$ (anatase) as shown in illustration in Fig. $5 \mathrm{~d}$.

The quality and atomic scale defects and clustering were further examined by atom probe tomography (APT) of the sample with highest Ti concentration, i.e., 5 at\% (GTO-100). Specifically, APT allows us to verify dopant clustering (if any) at the highest concentration. The APT specimens were lifted out using focused ion beam (FIB) using Omni Probe and mounted on the micro-post for annular milling. The APT reconstructions of GTO-100 specimen are shown in Fig. 6 with Ga atoms in red and Ti in blue. The APT reconstruction shows a $37.78 \times 35.98 \times 119.1 \mathrm{~nm} 3$ volume. From the APT reconstruction, Ti is evenly distributed through the entire film thickness and no noticeable cluster formation of Ti atoms even for the highest Ti concentration. Thus, the XANES and APT data accounts for the structural and chemical quality of the GTO films.

\section{Conclusions}

An approach based on selective doping of Ti into $\beta-\mathrm{Ga}_{2} \mathrm{O}_{3}$ is demonstrated to realize reliable and rapid response high-temperature oxygen sensors for utilization in power plants and transportation systems. In Ti doped $\beta$ - $\mathrm{Ga}_{2} \mathrm{O}_{3}$, a rapid response time of $\sim 4 \mathrm{~s}$ is noted for oxygen sensor operating at $700^{\circ} \mathrm{C}$. This is remarkably high $(\sim 20$ times $)$ compared to the intrinsic $\mathrm{Ga}_{2} \mathrm{O}_{3}$ or existing other oxygen sensors. Ti-doped $\beta-\mathrm{Ga}_{2} \mathrm{O}_{3}$ exhibits lowest activation energy, low $m$-value, good recovery time, and excellent repeatability. The structural and chemical analyses indicate the role of $\mathrm{Ti}$ in $\beta-\mathrm{Ga}_{2} \mathrm{O}_{3}$ to promote the sensor performance. We believe that there may be further options 
a

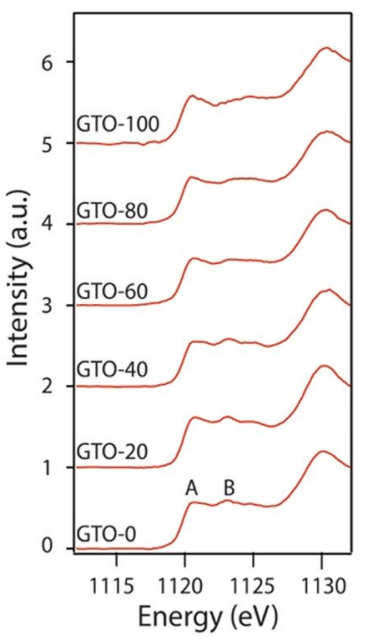

b

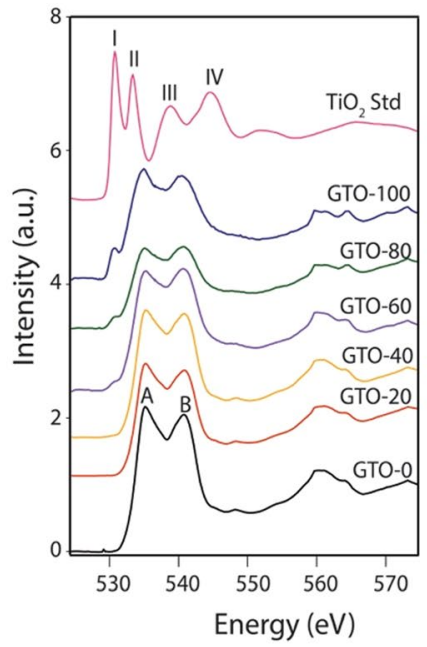

C

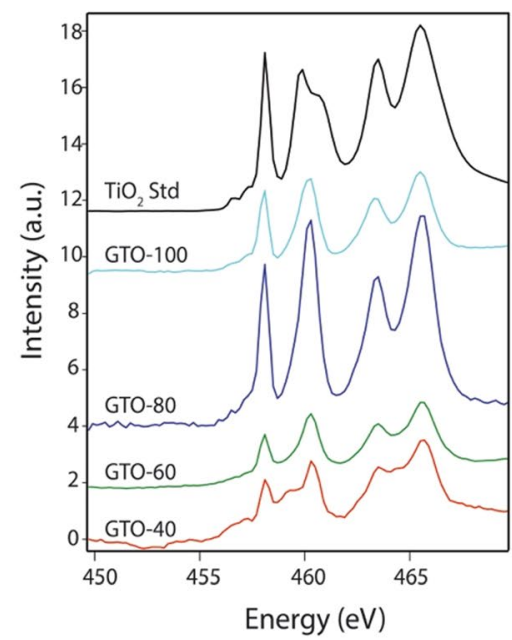

d

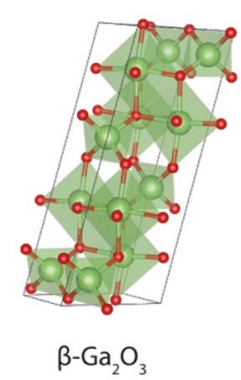

$0 \%$

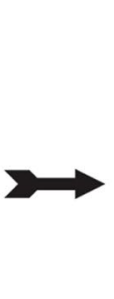

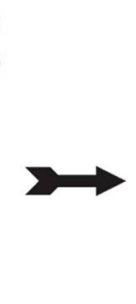

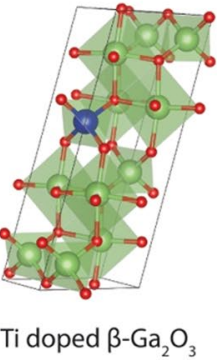

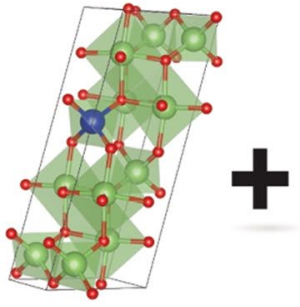

Ti doped $\beta-\mathrm{Ga}_{2} \mathrm{O}_{3}$

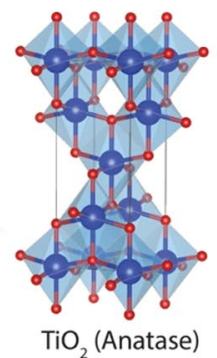

Ti concentration (at $\%)$

Figure 5. XANES spectra of Ga L edge, O K-edge, and Ti L-edge GTO films deposited with variable Ticoncentration. (a) Ga L-edge. (b) O K-edge. (c) Ti L-edge. (d) Illustration of Ti doping in $\mathrm{Ga}_{2} \mathrm{O}_{3}$ matrix.

available to further tune and improve the sensor performance while the underlying science and mechanisms may be applicable to a large class of "doped nanostructured oxides for sensor applications."

\section{Methods}

Sample preparation. Gallium oxide and Ti-incorporated $\mathrm{Ga}_{2} \mathrm{O}_{3}$ films were deposited onto silicon $(\mathrm{Si})$ and quartz with thin film Pt interdigitated finger electrodes with $100 \mu \mathrm{m}$ lines substrates by radio-frequency magnetron sputtering. Co-sputtering of the $\mathrm{Ga}_{2} \mathrm{O}_{3}(99.999 \%)$ and $\mathrm{Ti}$ (99.95\%) targets (2 in. diameter; Plasmaterials Inc.) was performed to produce GTO films. All the substrates were thoroughly cleaned and dried with nitrogen. The $\mathrm{Ga}_{2} \mathrm{O}_{3}$-and Ti targets were placed on 2-in. sputter guns, which were placed at $8 \mathrm{~cm}$ from the substrate. The base pressure was $\sim 10^{-6}$ Torr. A sputtering power of $25 \mathrm{~W}$ was initially applied to the targets while introducing high-purity argon (Ar) into the chamber to ignite the plasma. Once the plasma was ignited, the sputtering power was increased to the desired or set values for $\mathrm{Ga}_{2} \mathrm{O}_{3}$ and Ti targets, respectively. A constant sputtering power of $100 \mathrm{~W}$ was maintained for the $\mathrm{Ga}_{2} \mathrm{O}_{3}$ target. The Ti-target sputtering power was varied in the range of $0-100 \mathrm{~W}$ to vary the Ti concentration $(\mathrm{x})$ in the films. For clarity purposes, the sample identification is made with the sputtering power employed for deposition. Thus, the samples with variable Ti content are named GTO-0, GTO-20, GTO-40, GTO-60, GTO-80, and GTO-100, respectively, where the end numbers $(0-100)$ represent sputtering power applied to the Ti target. The flows of argon and oxygen were controlled using MKS mass flow meters. Before each deposition, the $\mathrm{Ga}_{2} \mathrm{O}_{3}$ target was pre-sputtered for $10 \mathrm{~min}$ with the shutter above the gun closed. The samples were deposited at a substrate temperature $\left(\mathrm{T}_{\mathrm{s}}\right)$ of $500^{\circ} \mathrm{C}$, which is optimum for producing nanocrystalline, $\beta$-phase $\mathrm{Ga}_{2} \mathrm{O}_{3}$ films ${ }^{19,46}$. The substrates were heated by resistive heating, and the desired $\mathrm{T}_{\mathrm{s}}$ was controlled by an Athena X25 controller. The time of deposition was kept constant at 3 hours. The doping of titanium on gallium oxide is done by substitutional of gallium site with titanium and creates gallium vacancies as shown below by Kroger-Vink notation:

$$
3 \mathrm{TiO}_{2} \stackrel{\mathrm{Ga}_{2} \mathrm{O}_{3}}{\longrightarrow} 3 \mathrm{Ti}_{\mathrm{Ga}} \cdot 6 \mathrm{O}_{\mathrm{O}}^{\mathrm{X}}+\mathrm{V}_{\mathrm{Ga}}^{\prime \prime \prime}
$$


a

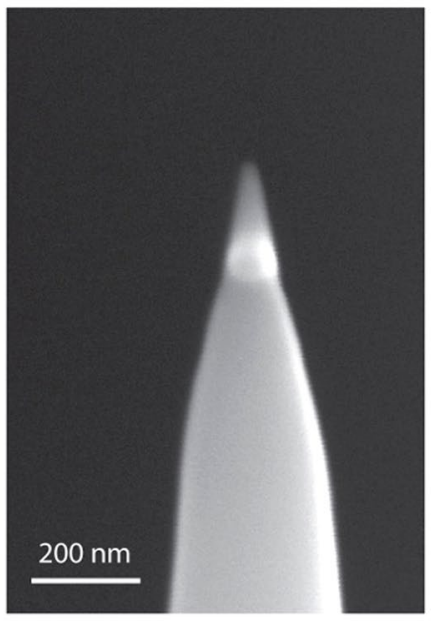

b

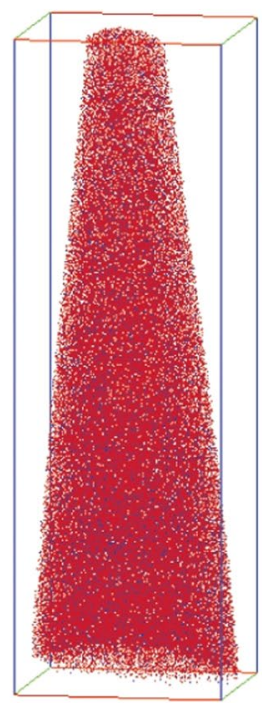

C

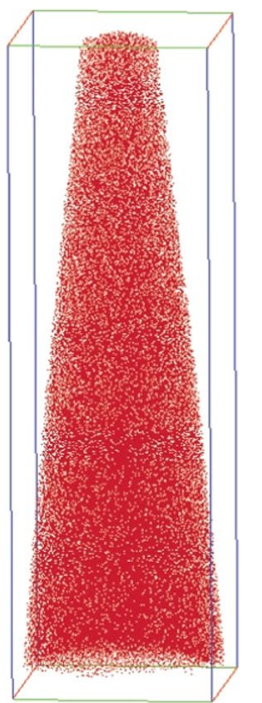

Ga atoms d

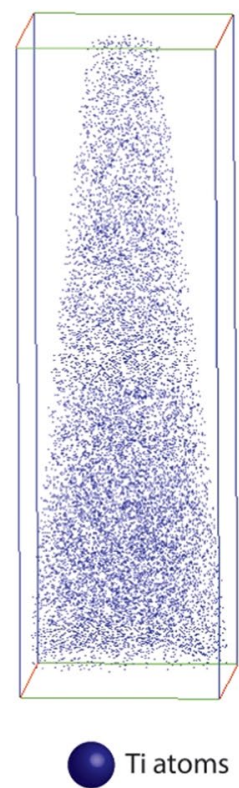

Figure 6. APT reconstruction of GTO-100 samples. (a) Sample tip as prepared after FIB annular milling. (b) All-atomic view of APT reconstruction showing Ga in red and Ti in blue. (c) Atomic view of only Ga atoms. (d) Atomic view of only Ti atoms.

The solubility of titanium in $\mathrm{Ga}_{2} \mathrm{O}_{3}$ can be simply explained by the comparing its ionic radii, i.e., $\mathrm{Ga}^{3+}$ has ionic radii of $0.047 \mathrm{~nm}$ and $0.062 \mathrm{~nm}$ for the coordination number of 4 and 6 while $\mathrm{Ti}^{4+}$ has ionic radii of $0.042 \mathrm{~nm}$ and $0.06 \mathrm{~nm}$ for the coordination number of 4 and $6^{35,47}$. They (Ga and Ti) also have similar electronegativity (1.6 Pau and 1.5 Pau respectively $)^{48}$.

X-ray absorption near edge structure (XANES). The XANES experiments were carried out at beamline 6.3.1 of Advanced Light Source (ALS) at Lawrence Berkeley National Laboratory (LBNL). Beamline 6.3.1 utilizes a variable line space (VLS) monochromator on a bend magnet source to provide photons with energies from 100 to $2200 \mathrm{eV}$ into a multi-purpose end-station that is like the end-station on Beamline 6.3.2. ${ }^{49}$. Reference Ti L-edge, $\mathrm{Mg} \mathrm{K}$-edge, and $\mathrm{O} \mathrm{K}$-edge spectra were also collected from $\mathrm{TiO}_{2}$ and $\mathrm{MgO}$ standards for calibration for different gratings used. Spectra were collected at room temperature in the total electron yield (TEY) mode with the signal obtained from the sample drain current. No substantial charging problems were detected. Ga L-edge, O K-edge, and Ti L-edge were collected for all samples.

Atom probe tomography (APT). APT samples were also prepared using the FEI Quanta dual beam FIB. The APT specimen preparation method by site-specific FIB lift-out and annular milling ${ }^{50,51}$. A CAMECA LEAP 4000XHR system equipped with pulsed UV laser ( $355 \mathrm{~nm}$ wavelength) was used to perform APT experiments using $40 \mathrm{pJ}$ laser pulse energy at the $100 \mathrm{kHz}$ frequency with specimen temperature of $40 \mathrm{~K}$. The APT results were reconstructed and analyzed using Interactive Visualization and Analysis Software (IVAS) 3.6.8 using standard reconstruction procedure ${ }^{51}$.

Transmission electron microscopy (TEM). TEM samples were prepared using lamella lift out procedure using dual beam FIB (FEI Helios) and mounted on copper half grids. The TEM was done using FEI Tecnai TEM using field emission gun operating with an accelerating voltage of $200 \mathrm{kV}$.

Oxygen sensor testing and evaluation. The sensor performance was evaluated at a temperature of $700^{\circ} \mathrm{C}$; the electrical measurements were recorded using Keithley 6514 electrometer, and the input current $(10 \mathrm{nA})$ was supplied via a Keithley 220 Programmable Current Source. Two gas tanks were employed for this investigation, a $99.99 \% \mathrm{Ar}$ as the baseline gas, and a $99.99 \% \mathrm{O}_{2}$ as the analyte gas; both gasses were controlled using an MKS mass flow controller to achieve different partial pressures of oxygen. All the sensor performance responses were recorded as a function of Ti sputtering power and Ti concentration and feature such sensitivity and time response are presented.

The activation energy was calculated using Eq. 1. The experiments were conducted at different partial pressures. Each partial pressure was subjected to 6 cycles $(\mathrm{N}=6)$ for repeatability. Each and every fitting procedure is carried out until the best fit ( $\mathrm{R}$ is greater than 0.9 or better) is achieved. The $\mathrm{R}$ values were obtained from fitting for each partial pressure along with the standard deviation which was used to calculate the final value of activation energy. The error of fitting is as reflected in the data graphs presented, where the error estimation and statistical standard deviation is also considered. 


\section{Data availability}

The necessary data required is included in the manuscript. The data available in the literature has been cited as needed and appropriate.

Received: 28 March 2018; Accepted: 16 October 2019; Published online: 13 January 2020

\section{References}

1. Gurney, K. R. et al. High Resolution Fossil Fuel Combustion CO2 Emission Fluxes for the United States. Environmental Science \& Technology 43, 5535-5541 (2009).

2. Rao, A. B. \& Rubin, E. S. A Technical, Economic, and Environmental Assessment of Amine-Based $\mathrm{CO}_{2}$ Capture Technology for Power Plant Greenhouse Gas Control. Environmental Science \& Technology 36, 4467-4475, https://doi.org/10.1021/es0158861 (2002).

3. Devaraj, A. et al. A low-cost hierarchical nanostructured beta-titanium alloy with high strength. Nature communications 7 (2016).

4. Raupach, M. R. et al. Global and regional drivers of accelerating $\mathrm{CO}_{2}$ emissions. Proceedings of the National Academy of Sciences 104, 10288-10293 (2007).

5. Canadell, J. G. et al. Contributions to accelerating atmospheric $\mathrm{CO} 2$ growth from economic activity, carbon intensity, and efficiency of natural sinks. Proceedings of the national academy of sciences 104, 18866-18870 (2007).

6. Eranna, G., Joshi, B., Runthala, D. \& Gupta, R. Oxide materials for development of integrated gas sensors-a comprehensive review. Critical Reviews in Solid State and Materials Sciences 29, 111-188 (2004).

7. Kiasari, N. M., Soltanian, S., Gholamkhass, B. \& Servati, P. Sketching functional, ubiquitous ZnO nano-sensors on paper. RSC Advances 4, 19663-19667 (2014).

8. Yun, D. H., Kim, D. \& Park, C. O. YSZ sensor for lean burn combustion system. Sensors and Actuators B: Chemical 13, 114-116 (1993).

9. Comini, E. et al. Quasi-One dimensional metal oxide semiconductors: Preparation, characterization and application as chemical sensors. Progress in Materials Science 54, 1-67 (2009).

10. Rubio, E. et al. Tungsten Incorporation into Gallium Oxide: Crystal Structure, Surface and Interface Chemistry, Thermal Stability, and Interdiffusion. The Journal of Physical Chemistry C 120, 26720-26735 (2016).

11. Rubio, E. \& Ramana, C. Tungsten-incorporation induced red-shift in the bandgap of gallium oxide thin films. Applied Physics Letters 102, $191913(2013)$

12. Fleischer, M., Höllbauer, L. \& Meixner, H. Effect of the sensor structure on the stability of $\mathrm{Ga}_{2} \mathrm{O}_{3}$ sensors for reducing gases. Sensors and Actuators B: Chemical 18, 119-124 (1994).

13. Frank, J., Fleischer, M., Meixner, H. \& Feltz, A. Enhancement of sensitivity and conductivity of semiconducting $\mathrm{Ga}_{2} \mathrm{O}_{3}$ gas sensors by doping with $\mathrm{SnO}_{2}$. Sensors and Actuators B: Chemical 49, 110-114 (1998).

14. Frank, J., Fleischer, M. \& Meixner, H. Electrical doping of gas-sensitive, semiconducting $\mathrm{Ga}_{2} \mathrm{O}_{3}$ thin films. Sensors and Actuators $B$ : Chemical 34, 373-377 (1996).

15. Fleischer, M. \& Meixner, H. Sensing reducing gases at high temperatures using long-term stable $\mathrm{Ga}_{2} \mathrm{O}_{3}$ thin films. Sensors and Actuators B: Chemical 6, 257-261 (1992).

16. Fleischer, M. \& Meixner, H. Gallium oxide thin films: a new material for high-temperature oxygen sensors. Sensors and Actuators B: Chemical 4, 437-441 (1991).

17. Baban, C., Toyoda, Y. \& Ogita, M. Oxygen sensing at high temperatures using $\mathrm{Ga}_{2} \mathrm{O}_{3}$ films. Thin Solid Films 484, 369-373 (2005).

18. Li, Y., Trinchi, A., Wlodarski, W., Galatsis, K. \& Kalantar-zadeh, K. Investigation of the oxygen gas sensing performance of $\mathrm{Ga}_{2} \mathrm{O}_{3}$ thin films with different dopants. Sensors and Actuators B: Chemical 93, 431-434, https://doi.org/10.1016/S0925-4005(03)00171-0 (2003).

19. Manandhar, S. \& Ramana, C. Direct, functional relationship between structural and optical properties in titanium-incorporated gallium oxide nanocrystalline thin films. Applied Physics Letters 110, 061902 (2017).

20. López, I. et al. Influence of $\mathrm{Sn}$ and Cr Doping on Morphology and Luminescence of Thermally Grown $\mathrm{Ga}_{2} \mathrm{O}_{3}$ Nanowires. The Journal of Physical Chemistry C 117, 3036-3045 (2013).

21. Zhang, Y. et al. Optical and structural properties of $\mathrm{Cu}-\mathrm{doped} \beta-\mathrm{Ga}_{2} \mathrm{O}_{3}$ films. Materials Science and Engineering: B 176, 846-849, https://doi.org/10.1016/j.mseb.2011.04.014 (2011).

22. Zinkevich, M. et al. Microstructural and thermodynamic study of $\gamma-\mathrm{Ga}_{2} \mathrm{O}_{3}$. Zeitschrift für Metallkunde 95, 756-762 (2004).

23. Roy, S. \& Ramana, C. V. Effect of Thermochemical Synthetic Conditions on the Structure and Dielectric Properties of $\mathrm{Ga}_{1.9} \mathrm{Fe}_{0.1} \mathrm{O}_{3}$ Compounds. Inorganic Chemistry, https://doi.org/10.1021/acs.inorgchem.7b02363 (2018).

24. Zavabeti, A. et al. A liquid metal reaction environment for the room-temperature synthesis of atomically thin metal oxides. Science 358, 332-335 (2017).

25. Chen, N. et al. $\mathrm{TiO}_{2}$ nanoparticles functionalized by $\mathrm{Pd}$ nanoparticles for gas-sensing application with enhanced butane response performances. Scientific Reports 7, 7692 (2017).

26. Wu, H. et al. One-step Synthesis of Ordered ${\mathrm{Pd} @ \mathrm{TiO}_{2}}_{2}$ Nanofibers Array Film as Outstanding $\mathrm{NH}_{3}$ Gas Sensor at Room Temperature. Scientific Reports 7, 14688 (2017).

27. Lu, H. F. et al. Amorphous $\mathrm{TiO}_{2}$ nanotube arrays for low-temperature oxygen sensors. Nanotechnology 19, 405504 (2008).

28. Lin, S., Li, D., Wu, J., Li, X. \& Akbar, S. A selective room temperature formaldehyde gas sensor using $\mathrm{TiO}_{2}$ nanotube arrays. Sensors and Actuators B: Chemical 156, 505-509 (2011).

29. Waser, R. \& Aono, M. Nanoionics-based resistive switching memories. Nature Materials 6, 833-840 (2007).

30. Moon, H. et al. Interfacial chemical bonding-mediated ionic resistive switching. Scientific Reports 7, 1264 (2017).

31. Shannon, R. D. Revised effective ionic radii and systematic studies of interatomic distances in halides and chalcogenides. Acta. Crystallography A 32, 751-767 (1976).

32. Schipani, F., Aldao, C. \& Ponce, M. Schottky barriers measurements through Arrhenius plots in gas sensors based on semiconductor films. AIP Advances 2, 032138 (2012).

33. Fleischer, M., Wagner, V., Hacker, G. \& Meixner, H. Comparision of ac and dc measurement techniques using semiconducting $\mathrm{Ga}_{2} \mathrm{O}_{3}$ sensors. Sensors and Actuators B: Chemical 26, 85-88 (1995).

34. Moseley, P. Materials selection for semiconductor gas sensors. Sensors and Actuators B: Chemical 6, 149-156 (1992).

35. Ramamoorthy, R., Dutta, P. \& Akbar, S. Oxygen sensors: materials, methods, designs and applications. Journal of materials science 38, 4271-4282 (2003).

36. Geller, S. Crystal Structure of $\beta-\mathrm{Ga}_{2} \mathrm{O}_{3}$. The Journal of Chemical Physics 33, 676-684 (1960).

37. Shimizu, K.-i. et al. Influence of local structure on the catalytic activity of gallium oxide for the selective reduction of $\mathrm{NO}$ by $\mathrm{CH}_{4}$. Chemical Communications, 1827-1828 (1996).

38. Calvin, S. XAFS for Everyone. (CRC press, 2013).

39. Agarwal, B. \& Verma, L. A rule for chemical shifts of X-ray absorption edges. Journal of Physics C: Solid State Physics 3, 535 (1970).

40. Wu, Z., Ouvrard, G., Gressier, P. \& Natoli, C. Ti and OK edges for titanium oxides by multiple scattering calculations: Comparison to XAS and EELS spectra. Physical Review B 55, 10382 (1997). 
41. De Groot, F. et al. Oxygen 1s x-ray-absorption edges of transition-metal oxides. Physical Review B 40, 5715 (1989).

42. Tourtin, F., Armand, P., Ibanez, A., Tourillon, G. \& Philippot, E. Gallium phosphate thin solid films: structural and chemical determination of the oxygen surroundings by XANES and XPS. Thin Solid Films 322, 85-92 (1998).

43. Van Der Laan, G. Polaronic satellites in x-ray-absorption spectra. Physical Review B 41, 12366 (1990).

44. Ruus, R. et al. Ti 2p and O 1s X-ray absorption of $\mathrm{TiO}_{2}$ polymorphs. Solid State Communications 104, 199-203 (1997).

45. Crocombette, J. \& Jollet, F. Ti $2 \mathrm{p} \mathrm{x}$-ray absorption in titanium dioxides $\left(\mathrm{TiO}_{2}\right)$ : the influence of the cation site environment. Journal of Physics: Condensed Matter 6, 10811 (1994).

46. Kumar, S. S. et al. Structure, morphology, and optical properties of amorphous and nanocrystalline gallium oxide thin films. The Journal of Physical Chemistry C 117, 4194-4200 (2013).

47. Shannon, R. \& Prewitt, C. Coordination and volume changes accompanying high-pressure phase transformations of oxides. Materials Research Bulletin 4, 57-62 (1969).

48. Dakhel, A. A. Investigation of opto-dielectric properties of Ti-doped $\mathrm{Ga}_{2} \mathrm{O}_{3}$ thin films. Solid State Sciences 20, 54-58, https://doi. org/10.1016/j.solidstatesciences.2013.03.009 (2013).

49. Underwood, J. H. \& Gullikson, E. M. High-resolution, high-flux, user friendly VLS beamline at the ALS for the 50-1300eV energy region. Journal of electron spectroscopy and related phenomena 92, 265-272 (1998).

50. Thompson, K. et al. In situ site-specific specimen preparation for atom probe tomography. Ultramicroscopy 107, 131-139 (2007).

51. Larson, D. J., Prosa, T. J., Ulfig, R. M., Geiser, B. P. \& Kelly, T. F. Local electrode atom probe tomography. NY: Springer, New York (2013).

\section{Acknowledgements}

The authors acknowledge, with pleasure, support from the National Science Foundation (NSF) with grant \# ECCS-1509653. The APT characterizations were carried out at the Environmental Molecular Sciences Laboratory (EMSL), a National Scientific User Facility located at the Pacific Northwest National Laboratory (PNNL) and supported by the U.S. DOE Office of Biological and Environmental Research. PNNL is operated by Battelle Memorial Institute for the U.S. DOE under contract DE-AC 06-76RLO 1830. XAFS measurement was carried out at beamline at Advance Light Source (ALS) in Lawrence Berkeley National Laboratory (LBNL). CVR also acknowledges the NSF-PREM grant \#DMR-1827745.

\section{Author contributions}

C.V.R. conceived and supervised the research. S.M. and A.K.B. deposited the samples and fabricated sensors. S.M., A.K.B. and C.V.R. characterized the samples. A.D. and S.M. characterized the samples by A.P.T., S.T. and S.M. performed the XANES measurements. CVR coordinated the project and scientific contributions from all the authors. All authors were involved in data analyses, designed figures, and wrote the manuscript. S.M. and C.V.R. coordinated to collect the comments and feedback from all co-authors.

\section{Competing interests}

The authors declare no competing interests.

Additional information

Correspondence and requests for materials should be addressed to C.V.R.

Reprints and permissions information is available at www.nature.com/reprints.

Publisher's note Springer Nature remains neutral with regard to jurisdictional claims in published maps and institutional affiliations.

Open Access This article is licensed under a Creative Commons Attribution 4.0 International License, which permits use, sharing, adaptation, distribution and reproduction in any medium or format, as long as you give appropriate credit to the original author(s) and the source, provide a link to the Creative Commons license, and indicate if changes were made. The images or other third party material in this article are included in the article's Creative Commons license, unless indicated otherwise in a credit line to the material. If material is not included in the article's Creative Commons license and your intended use is not permitted by statutory regulation or exceeds the permitted use, you will need to obtain permission directly from the copyright holder. To view a copy of this license, visit http://creativecommons.org/licenses/by/4.0/.

(C) The Author(s) 2020 